The Egyptian Journal of Hospital Medicine (July 2019) Vol. 76 (7), Page 4459-4468

\title{
The Prognostic Value of Left Ventricular Function on Sepsis Outcomes in Critical Care Unit Patients
}

Hossam Eldeen Salah Shabanh ${ }^{1}$, Abdellah Hussein Al-sadek ${ }^{1}$, Ibrahim Farag-Allah Said ${ }^{2}$, Ahmed Mohammed Said Sallam*1

Departments of ${ }^{1}$ Internal Medicine $\&{ }^{2}$ Cardiology, Faculty of Medicine, Al-Azhar University

*Corresponding author: Ahmed Mohammed Said Sallam, E-mail: drsallam.2030@gmail.com

\begin{abstract}
Background: Sepsis is the most prevalent life menacing condition presupposed patients' admission to intensive care units. The underlying cardiovascular consequences of sepsis comprehended marvelous increase of the cardiac output, reduction of the peripheral vascular resistance along with impaired capillary permeability.

Aim of the study: The present investigation was implemented to retrieve the prognostic value of LVF assessment using speckle tracking echocardiography (STE) among Egyptian adults, who admitted to the intensive care unit as a resultant impact of sepsis or septic shock.

Methods: Patients admitted at the Critical Care Unit, who initially diagnosed with sepsis or septic shock within 8 hours. After fulfilling their criteria and being aged more than 18 years, they were eligible for inclusion in the study. All participants were submitted to rigorous history taking, clinical evaluation, laboratory assessment, and STE. The study embraced an overall 50 patients..

Results: Left ventricular longitudinal strain (LVGLS) was the only parameter which attained statistically significant highly positive correlation with SOFA score among septic shock patients $(r=0.794, p=0.021)$. The results of this model revealed that LVGLS $(\mathrm{p}<0.001)$ attained high ability in the prediction of Sepsis-related Organ Failure Assessment (SOFA) score and Acute Physiologic and Chronic Health Evaluation (APACHE) score.

Conclusions: The capability of STE investigation for the detection of left ventricular dysfunction among septic or septic shocked critically ill patients is a promising and feasible approach, which have a crucial impact on the prognosis of such patients.
\end{abstract}

Keywords: Septic shock, Sepsis, speckle tracking echocardiography.

\section{INTRODUCTION}

Sepsis is the most prevalent life menacing condition presupposed patients' admission to intensive care units (1). This is because its underlying sequels such as hemodynamic instability, inadequate tissue oxygenation, and multi-organ failure, which in turn leads to increased risk of mortality (2). To date, approximately 750,000 septic cases are diagnosed annually in the United States, which unfortunately harvested more than 200,000 death per year ${ }^{(3,4)}$.

The underlying cardiovascular consequences of sepsis comprehended marvelous increase of the cardiac output, reduction of the peripheral vascular resistance along with impaired capillary permeability ${ }^{(5)}$. These complications altered significantly the cardiac function, which in turn develop septic cardiomyopathy ${ }^{(6,7)}$.

Throughout the past era, evaluation of cardiac function was assessed using Swan-Ganz Catheter; in addition, echocardiography has been established as a pivotal diagnostic tool in the appreciation of the morphological and functional characteristics of the heart among septic patients ${ }^{(8,9)}$. Subsequent to that, new modalities have been established recently, particularly 3D echocardiography, speckle tracking echocardiography (STE) and tissue Doppler ${ }^{(10)}$. Not only did these techniques attain precise evaluation of the cellular function of the heart, but they also had a crucial rule in the prognosis and the detection of the appropriate treatment strategies ${ }^{(\mathbf{1 0}, \mathbf{1 1})}$.

The myocardial function has been frequently evaluated based upon ejection fraction (EF), 2D echocardiography and M mode echocardiography ${ }^{(12)}$. Conversely, these diagnostic tools had several limitations in order that their results are influenced dramatically by pre-load, after load, and heart rate ${ }^{(\mathbf{1 3})}$. Thereafter, the optimal and the early detection of septic cardiomyopathy is remaining challengeable owed to the obscurity of adequate test with high sensitivity and specificity for early diagnosis and proper monitoring of the myocardial function ${ }^{(14)}$. To overcome these obstacles, STE has been evolved with a considerable quantitative and objective assessment of the left ventricular function (LVF) regardless of the insonation angle ${ }^{(15)}$.

The present investigation was implemented to retrieve the prognostic value of LVF assessment using STE among Egyptian adults, who were admitted to the Intensive Care Unit at El-Hussein University Hospital as a resultant impact of sepsis or septic shock. 
ejhm.journals.ekb.eg

\section{METHODS}

This study is a prospective observational casecontrol study, which was implemented at the Internal Medicine Department, El-Hussein University Hospital, Faculty of Medicine, Al-Azhar University, Cairo throughout the entire period June 2018 to January 2019.

\section{Ethical approval}

The present study was approved by the Ethical Research Board of the Faculty of Medicine, AlAzhar University, Cairo. The potential risk events and complications were illustrated obviously for included patients, legal trustee or their relatives prior to study implementation. Informed consents were obtained before study conduction. Furthermore, all clinical and interventional procedures were executed along with the guidelines of the Declaration of Helsinki.

\section{Selection criteria}

Patients admitted at the Critical Care Unit, who were initially diagnosed with sepsis or septic shock within 8 hours. After fulfilling their criteria and aged more than 18 years old, they were eligible for inclusion in the study.

Exclusion criteria: On the contrary, patients with valvular or congenital heart disease and patients with primary cardiomyopathy were excluded. Additionally, patients with interstitial lung disease, chronic obstructive pulmonary disease or other primary lung diseases were omitted. Patients with previous intense diseases which may alter the cardiac hemodynamics or cardiac dysfunction were excluded.

Sepsis was identified based on the coexistence of more than two of the following criteria; fever $\left(>38^{\circ} \mathrm{C}\right)$ or hypothermia $\left(<35^{\circ} \mathrm{C}\right)$, respiratory rate $>20$ breaths/minute, heart rate $>90$ beats per minute or arterial partial pressure of carbon dioxide $<32 \mathrm{~mm} \mathrm{Hg}$, white cell count $<4000$ cells $/ \mathrm{mm}^{3}$ or $>12000$ cells $/ \mathrm{mm}^{3}$, or presence of immature forms $>10 \%$. Consequently, septic shock was established when the systolic blood pressure dropped abruptly more than $40 \mathrm{~mm} \mathrm{Hg}$ from initial values or the value of $\mathrm{SBP}<90 \mathrm{~mm} \mathrm{Hg}$, even though all patients were subjected adequate fluid resuscitation which required vasopressor administration.

\section{Clinical evaluation}

All participants were submitted to rigorous history talking and clinical evaluation to reveal the following parameters; patients age, sex, co-morbidities, cause of sepsis, Glasgow Coma Scale (GCS), heart rate, temperature, respiratory rate, systolic blood pressure, diastolic blood pressure, mean arterial blood pressure, and central venous pressure.

To appreciate the severity of sepsis, Sepsis-related Organ Failure Assessment (SOFA) score and Acute
Physiologic and Chronic Health Evaluation (APACHE) score were performed for all patients along with close monitoring of the arterial blood lactate concentration.

\section{Laboratory evaluation}

Laboratory evaluation was implemented for all participants comprehending blood profile, random blood sugar (RBS), arterial blood gases, electrolyte profile, serum creatinine, Alanine Transaminase (ALT), Aspartate Amino-transferase (AST), total bilirubin, and direct bilirubin.

\section{Echocardiography}

Based on the recommendations of the American and European Societies of Echocardiography (16), Echocardiography was executed within 1 day of admission and at the day of discharge using the same device (iE33, Philips Medical System, Andover, MA $)^{(17)}$. Strain measurements were performed using a validated, vendor-independent, 2D speckle-tracking echocardiographic tracking software (2D Cardiac Performance Analysis v1.1; TomTec Imaging Systems, Unterschleissheim, Germany) ${ }^{(17)}$ and using frame rates of 40-70 fps/sec for all measurements. All images were interpreted in a blinded approach by two Echocardiologists, regardless of admission time or clinical diagnosis, to ensure the highest level of quality.

The images were obtained while the patients lying in the left lateral position or supine position. All candidates were subjected to comprehensive evaluation using 2-dimensional (2D) and color flow Doppler valvular. Left ventricular ejection fraction was evaluated by 2 plane approach based on the Simpson's methodology ${ }^{(18)}$.

The Strain was evaluated by tracing the endocardial border of the left ventricle, whereby the best endocardial border was recognized when it passed the maximal number of segments. Additionally, the longitudinal strain was assessed in the apical view of the four chambers. On the other hand, circumferential and radial strains were appreciated in the parasternal short axes view. Subsequent to that, peak systolic strain was assessed using an average of three successive cardiac cycles.

\section{Statistical analysis}

Statistical analysis was performed using SPSS software version 23 for Windows (SPSS Inc., Chicago, IL, USA), and MedCalc software version 14.8 (MedCalc Software, Mariakerke, Belgium). Continuous normally distributed parameters were explicated in the form of mean and standard deviation (SD), and its specific groups were compared using student t-test. Conversely, non-normally distributed data were expressed using median and range and were compared 
using Man Whitney U test. Additionally, continuous normally distributed paired data were contrasted using paired T-test. Categorical variables were illustrated using the number, and percentage and its particular groups were compared using Pearson's chi-square test with Fisher's exact test. Correlation analysis was implemented using Pearson correlation coefficient for continuous normally distributed data. The univariate linear regression model was performed to retrieve the potential independent predictors of SOFA and APACHE scores using t-test analysis. The significant difference was established when $P<0.05$.

\section{RESULTS}

Patients demographic characteristics

This study embraced an overall 50 patients. Of them, 25 participants were assorted in the septic shock group, whilst the remaining 25 patients belonged to the sepsis group. The mean age of the included candidates was $60.88 \pm 11.39$ and $55.52 \pm 10.71$ years in the septic shock and sepsis groups, respectively. The main cause of sepsis was infected bedsores, whereby $20 \%$ of the patients enrolled in such groups experienced that cause. Furthermore, pneumonia contributed $16 \%$ and $20 \%$ of developing of septic shock and sepsis, respectively. There was a statistically significant difference between both groups in the term of GCS $(\mathrm{P}=0.026)$, respiratory rate (0.038), and SBP (0.29) (Table 1 and Figure 1).

Having the laboratory evaluation, patients enrolled in the septic shock and sepsis groups revealed statistically significant difference regarding the mean values of $\mathrm{HB}$, RBS, $\mathrm{PaO} 2$, So2, total bilirubin, direct bilirubin, total lactate, SOFA score, and APACHE score with p-values of $0.003,0.015,<0.001,<0.001,0.002$, $0.005,0.005,0.041$, and 0.039 , subsets, respectively. On the contrary, both groups did not elucidate a statistically significant difference in the meaning of TLC, PLT, PCV, HCO3, Na, K, AST, and ALT (Table 2 and Figure 2).

(1): Demographics and clinical characteristics of the included participants

\begin{tabular}{|c|c|c|c|}
\hline \multirow[t]{2}{*}{ Variables } & Septic Shock & Sepsis & \multirow{2}{*}{ P-Value } \\
\hline & Mean \pm SD / Number (\%) & Mean \pm SD / Number (\%) & \\
\hline Age & $60.88 \pm 11.39$ & $55.52 \pm 10.71$ & 0.535 \\
\hline Sex (Female) & $16(64 \%)$ & $14(56 \%)$ & 0.387 \\
\hline \multicolumn{3}{|l|}{ Cause of sepsis } & 0.312 \\
\hline Infected diabetic foot & $1(4 \%)$ & $2(8 \%)$ & \\
\hline Pyonephrosis & $2(8 \%)$ & $1(4 \%)$ & 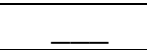 \\
\hline peritonitis & $3(12 \%)$ & $1(4 \%)$ & \\
\hline Pneumonia & $4(16 \%)$ & $5(20 \%)$ & - \\
\hline Infected Bed sores & $5(20 \%)$ & $5(20 \%)$ & \\
\hline Empyema & $4(16 \%)$ & $0(0 \%)$ & \\
\hline Infected central catheter & $4(16 \%)$ & $3(12 \%)$ & \\
\hline Bronchopneumonia & $1(4 \%)$ & $0(0 \%)$ & $=$ \\
\hline Pyelonephritis & $1(4 \%)$ & $4(16 \%)$ & $=$ \\
\hline Lung abscess & $0(0 \%)$ & $2(8 \%)$ & \\
\hline gluteal abscess & $0(0 \%)$ & $1(4 \%)$ & 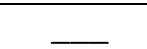 \\
\hline meningitis & $0(0 \%)$ & $1(4 \%)$ & \\
\hline GCS & $11.40 \pm 1.77$ & $12.8 \pm 1.2$ & $\overline{0.026}$ \\
\hline Temperature & $38.41 \pm 0.746$ & $38.85 \pm 4.972$ & 0.99 \\
\hline Heart rate & $111.52 \pm 9.79$ & $102.48 \pm 7.68$ & 0.229 \\
\hline Respiratory rate & $25.84 \pm 2.034$ & $24.32 \pm 2.96$ & 0.038 \\
\hline SBP & $73.60 \pm 9.52$ & $102.8 \pm 6.78$ & 0.029 \\
\hline DBP & $38 \pm 7.07$ & $63.60 \pm 9.07$ & 0.165 \\
\hline MAP & $49.44 \pm 5.22$ & $76.32 \pm 4.97$ & 0.407 \\
\hline CVP & $4.40 \pm 1.89$ & $4.64 \pm 1.70$ & 0.529 \\
\hline
\end{tabular}




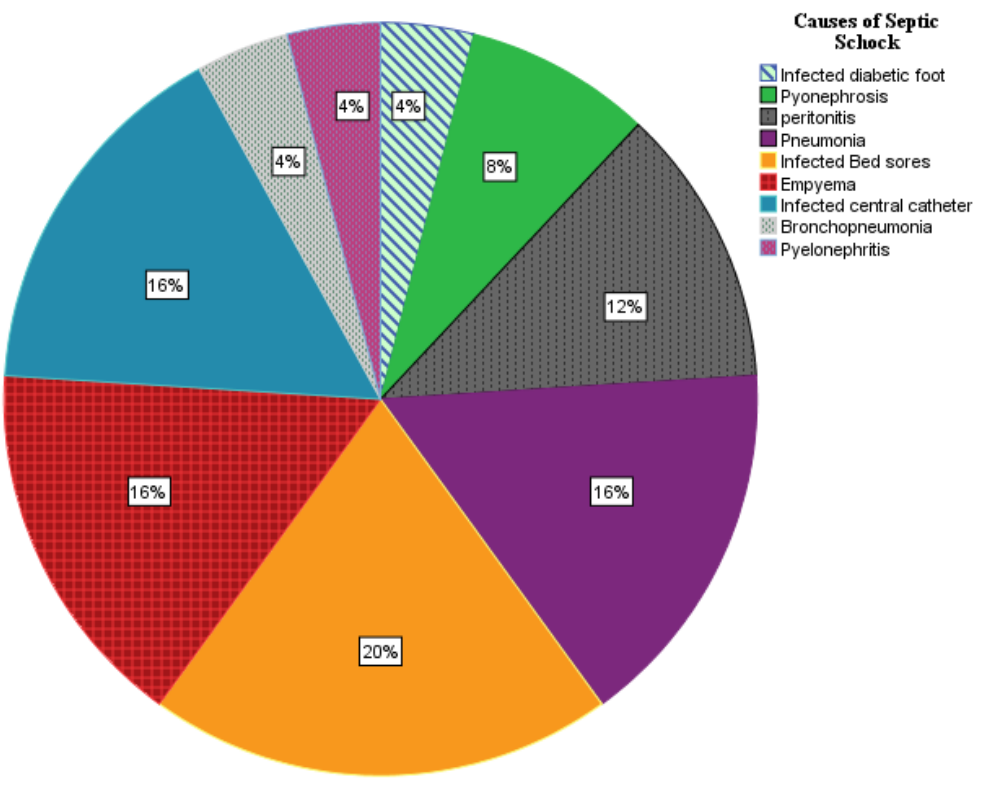

Figure (1): Pie chart depicted the underlying etiologies of septic shock

Table (2): Laboratory characteristics of the included participants

\begin{tabular}{|c|c|c|c|}
\hline \multirow[t]{2}{*}{ Variables } & Septic Shock & Sepsis & \multirow[t]{2}{*}{ P-Value } \\
\hline & Mean \pm SD / Number (\%) & Mean \pm SD / Number (\%) & \\
\hline HB (g/dL) & $8.80 \pm 0.59$ & $9.75 \pm 1.09$ & 0.003 \\
\hline TLC & $23.66 \pm 5.115$ & $19.84 \pm 5.31$ & 0.93 \\
\hline PLT (mcL) & $90.88 \pm 18.68$ & $85.66 \pm 20.22$ & 0.73 \\
\hline PCV & $28.69 \pm 3.69$ & $30.88 \pm 3.52$ & 0.83 \\
\hline RBS (mmol/l) & $275.08 \pm 92.79$ & $207.36 \pm 48.93$ & 0.015 \\
\hline Serum Creatinine $(\mathrm{mg} / \mathrm{dL})$ & $3.39 \pm 1.66$ & $2.30 \pm 1.096$ & 0.054 \\
\hline $\mathrm{PH}$ & $7.142 \pm 0.062$ & $7.218 \pm 0.063$ & 0.85 \\
\hline $\mathrm{HCO} 3(\mathrm{mEq} / \mathrm{L})$ & $9.70 \pm 2.81$ & $13.92 \pm 2.16$ & 0.075 \\
\hline $\mathrm{PaO} 2(\mathrm{mmHg})$ & $71.52 \pm 15.7$ & $88.04 \pm 7.334$ & $<0.001$ \\
\hline $\mathrm{PaCo} 2(\mathrm{mmHg})$ & $24.84 \pm 2.57$ & $28 \pm 2.92$ & 0.266 \\
\hline So2 (ppm) & $88.72 \pm 4.188$ & $92.8 \pm 2.08$ & $<0.001$ \\
\hline $\mathrm{Na}$ & $126.68 \pm 4.04$ & $130.76 \pm 3.33$ & 0.240 \\
\hline $\mathrm{K}$ & $4.64 \pm 0.76$ & $3.95 \pm 0.823$ & 0.89 \\
\hline AST (U/L) & $44 \pm 4 *$ & $34 \pm 1^{*}$ & 0.54 \\
\hline ALT (U/L) & $43 \pm 1 *$ & $30 \pm 1 *$ & 0.35 \\
\hline Total Bilirubin $(\mu \mathrm{mol} / \mathrm{L})$ & $1.8 \pm 0.04^{*}$ & $0.9 \pm 0.04^{*}$ & 0.49 \\
\hline Direct Bilirubin $(\mu \mathrm{mol} / \mathrm{L})$ & $0.8 \pm 0.01 *$ & $0.4 \pm 0.01 *$ & 0.002 \\
\hline Lactate & $5.240 \pm 1.65$ & $4.39 \pm 1.024$ & 0.005 \\
\hline \multicolumn{3}{|l|}{ Culture } & 0.623 \\
\hline Positive blood & $15(60 \%)$ & $13(52 \%)$ & ב- \\
\hline Positive Urine & $3(15 \%)$ & $4(20 \%)$ & \\
\hline Positive sputum & $5(25 \%)$ & $5(25 \%)$ & 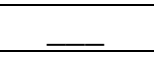 \\
\hline Positive blood\& sputum & $2(10 \%)$ & $1(5 \%)$ & ב- \\
\hline Negative & $0(0 \%)$ & $2(10 \%)$ & \\
\hline SOFA Score & $7.72 \pm 1.88$ & $5.72 \pm 1.69$ & 0.041 \\
\hline APACH Score & $27.04 \pm 4.99$ & $16.28 \pm 4.72$ & 0.039 \\
\hline \multicolumn{4}{|c|}{ 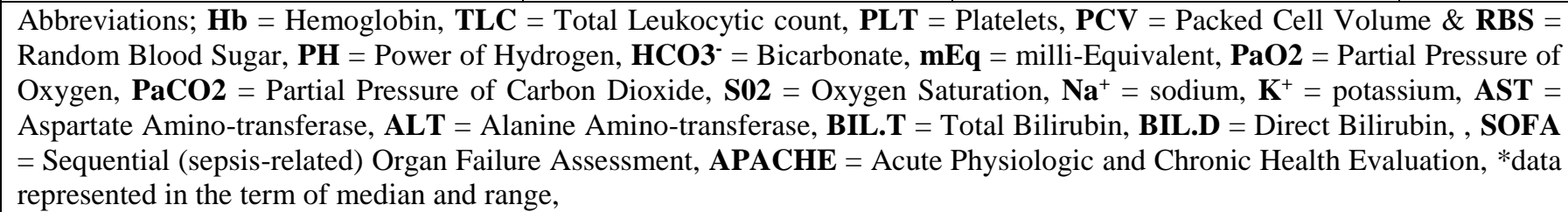 } \\
\hline
\end{tabular}




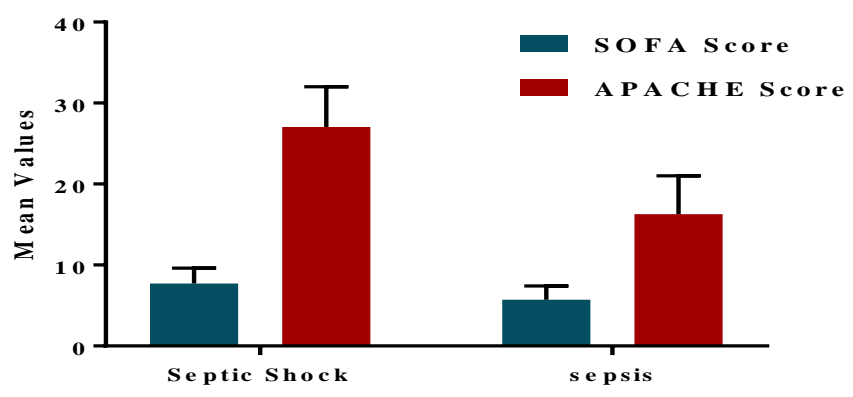

Figure (2): Error bar chart delineated the mean difference between SOFA and APACH scores among septic shock and sepsis groups.

\section{Echocardiographic characteristics}

The Echocardiographic characteristics of septic shock patients differed substantially between the day of admission and the day of discharge. In particular, the mean values of EF ( $p<0.001)$, maximum flow velocity during late diastolic LV filling ( $\mathrm{p}<0.001)$, late diastolic annulus velocity $(\mathrm{p}<0.001)$ and LV GLS $(\mathrm{p}=0.033)$ with mean of 50.86 $\pm 4.003,85.09 \pm$ $15.47,7.57 \pm 1.07$ and $-13.04 \pm 1.46$ at admission and $60.68 \pm 1.756,59.5 \pm 7.70,9.172 \pm 0.63$ and $-16.15 \pm 8.064$ at discharge, respectively (table 3). Turning to the remaining set of data, the Echocardiographic variables differed noticeably among septic patients at the day of admission and the day of discharge, whereby the functional outcomes enhanced dramatically at the day of discharge in the merits of $\mathrm{EF}$, maximum flow velocity during early LV diastolic filling, maximum flow velocity during late diastolic LV filling, Early diastolic annulus velocity, late diastolic annulus velocity, and LV GLS with mean values of $63.30 \pm 2.40,69.21 \pm 10.81,55.56 \pm 8.54,10.813 \pm 0.651,11.25 \pm 1.245,6.44 \pm 1.21$, and $-18.55 \pm$ 0.899 , respectively, at the day of discharge (Table 4).

\begin{tabular}{|c|l|l|l|}
\hline \multicolumn{3}{|c|}{ (3): The Echocardiographic characteristics of patients with septic shock on Admission \& on Discharge } \\
\cline { 1 - 3 } & At admission & At Discharge & \multirow{2}{*}{ P-Value } \\
\cline { 2 - 4 } & Mean \pm SD & Mean \pm SD & $<0.001$ \\
\hline EF \% & $50.86 \pm 4.003$ & $60.68 \pm 1.756$ & 0.006 \\
\hline E (cm/sec) & $94.45 \pm 11.96$ & $76.72 \pm 9.077$ & $<0.001$ \\
\hline A (cm/sec) & $85.09 \pm 15.47$ & $59.5 \pm 7.70$ & 0.22 \\
\hline $\mathbf{E} / \mathbf{A}$ & $1.12 \pm 0.195$ & $1.29 \pm 0.17$ & $<0.001$ \\
\hline $\mathbf{a}$ & $7.57 \pm 1.07$ & $9.172 \pm 0.63$ & $<0.001$ \\
\hline $\mathbf{e} / \mathbf{a}$ & $9.76 \pm 1.97$ & $11.63 \pm 0.876$ & 0.385 \\
\hline E/e & $0.774 \pm 0.076$ & $0.75 \pm 0.169$ & 0.113 \\
\hline LV GLS (\%) & $12.51 \pm 0.821$ & $8.353 \pm 0.753$ & 0.033 \\
\hline
\end{tabular}

Abbreviations; $\mathbf{E F}=$ Ejection Fraction, $\mathrm{E}=$ maximum flow velocity during early LV diastolic filling, $\mathbf{A}=$ maximum flow velocity during late diastolic LV filling, LV GLS = global systolic strain, $\mathbf{e}^{`}=$ Early diastolic annulus velocity, $\mathbf{a} `=$ late diastolic annulus velocity.

\begin{tabular}{|c|c|c|c|}
\hline \multirow[t]{2}{*}{ Variables } & At admission & At Discharge & \multirow[t]{2}{*}{ P-Value } \\
\hline & Mean \pm SD & Mean \pm SD & \\
\hline EF \% & $59.26 \pm 4.53$ & $63.30 \pm 2.40$ & $<0.001$ \\
\hline $\mathrm{E}(\mathrm{cm} / \mathrm{sec})$ & $101.6 \pm 11.51$ & $69.21 \pm 10.81$ & $<0.001$ \\
\hline $\mathrm{A}(\mathrm{cm} / \mathrm{sec})$ & $81 \pm 9.44$ & $55.56 \pm 8.54$ & $<0.001$ \\
\hline E/A & $1.25 \pm 0.091$ & $1.248 \pm 0.159$ & 0.89 \\
\hline è & $9.96 \pm 0.593$ & $10.813 \pm 0.651$ & $<0.001$ \\
\hline a & $9.96 \pm 1.458$ & $11.25 \pm 1.245$ & $<0.001$ \\
\hline $\mathbf{e}^{\prime} / \mathbf{a}^{\prime}$ & $1.01 \pm 0.12$ & $0.963 \pm 0.085$ & 0.016 \\
\hline E/e & $10.27 \pm 1.616$ & $6.44 \pm 1.21$ & $<0.001$ \\
\hline LV GLS (\%) & $-15.77 \pm 1.35$ & $-18.55 \pm 0.899$ & $<0.001$ \\
\hline
\end{tabular}

Abbreviations, $\mathbf{E F}=$ Ejection Fraction, $\mathrm{E}=$ maximum flow velocity during early LV diastolic filling, $\mathbf{A}=$ maximum flow velocity during late diastolic $\mathrm{LV}$ filling, LV GLS = global systolic strain, e` = Early diastolic annulus velocity, a` = late diastolic annulus velocity. 


\section{Correlation and regression analysis}

Having the septic shock group, LVGLS was the only parameter, which attained statically significant highly positive correlation with SOFA score $(\mathrm{r}=0.794, \mathrm{p}=$ $0.021)$. On the contrary, among septic patients, EF ( $\mathrm{r}=-$ $0.475, \mathrm{p}=0.016), \mathrm{E}(0.457, \mathrm{p}=0.022)$, e $(\mathrm{r}=-0.419, \mathrm{p}=$ $0.037)$, and $\mathrm{a}^{\prime}(\mathrm{r}=-0.428, \mathrm{p}=0.032)$ accomplished statistically significant correlation with SOFA score. In addition, LVGLS revealed statically very high positive correlation $(\mathrm{r}=0.847, \mathrm{p}=0.0015)$ with SOFA score (Table 5 and Figure 3).

Of note, among septic shock participants, heart rate accomplished statistically significant high positive correlation with APACHE score $(r=0.619, p<0.001)$. In addition, LV GLS attained very high positive correlation with APACHE score $(r=0.895, \mathrm{p}<0.001)$. Regarding the septic patients, EF revealed very high inverse correlation $(\mathrm{r}=-0.804, \mathrm{p}<0.001)$ with APACHE score, whereas LV GLS parameter achieved very high positive correlation ( $\mathrm{r}$ $=0.903, \mathrm{p}<0.001)$ with APACHE score $($ Table 6 and figure 4).

Univariate regression model was implemented to retrieve the potential predictors of SOFA and APACHE score. The results of this model revealed that LV GLS $(\mathrm{p}<0.001), \mathrm{EF}(\mathrm{p}<0.001)$ and early diastolic annulus velocity $(\mathrm{p}<0.001)$ attained high ability in the prediction of SOFA score. Similarly, these parameters accomplished highly predictive ability of the APACHE score (Table 7).

(5): Correlation between the clinical and echocardiological parameters and SOFA score

\begin{tabular}{|c|c|c|c|c|}
\hline \multirow{2}{*}{ Variables } & \multicolumn{2}{|c|}{ Septic shock } & \multicolumn{2}{c|}{ Sepsis } \\
\cline { 2 - 5 } & Correlation Co-efficient (r) & P-Value & Correlation Co-efficient (r) & P-Value \\
\hline Heart rate & 0.236 & 0.25 & -0.238 & 0.25 \\
\hline SBP & 0.174 & 0.40 & 0.034 & 0.86 \\
\hline DBP & -0.075 & 0.72 & -0.04 & 0.84 \\
\hline MAP & 0.038 & 0.85 & -0.038 & 0.85 \\
\hline EF \% & -0.342 & 0.09 & -0.475 & 0.016 \\
\hline $\mathbf{E ~ ( c m / s e c ) ~}$ & -0.474 & 0.017 & 0.457 & 0.022 \\
\hline $\mathbf{A}$ (cm/sec) & -0.27 & 0.18 & 0.233 & 0.261 \\
\hline $\mathbf{E / A}$ & -0.106 & 0.61 & 0.298 & 0.147 \\
\hline $\mathbf{e}$ & -0.394 & 0.051 & -0.419 & 0.037 \\
\hline $\mathbf{a}$ & -0.371 & 0.067 & -0.428 & 0.032 \\
\hline $\mathbf{e} / \mathbf{a}$ & 0.321 & 0.116 & 0.389 & 0.054 \\
\hline E/e & -0.167 & 0.42 & 0.490 & 0.083 \\
\hline LV GLS (\%) & 0.794 & 0.021 & 0.847 & 0.0015 \\
\hline
\end{tabular}

Abbreviations; SBP = Systolic Blood Pressure, DBP = Diastolic Blood Pressure, MAP = Mean Arterial Pressure, EF = Ejection Fraction, $\mathrm{E}=$ maximum flow velocity during early LV diastolic filling, $\mathbf{A}=$ maximum flow velocity during late diastolic LV filling, LV GLS $=$ global systolic strain, $\mathbf{e}^{`}=$ Early diastolic annulus velocity, $\mathbf{a}^{`}=$ late diastolic annulus velocity.
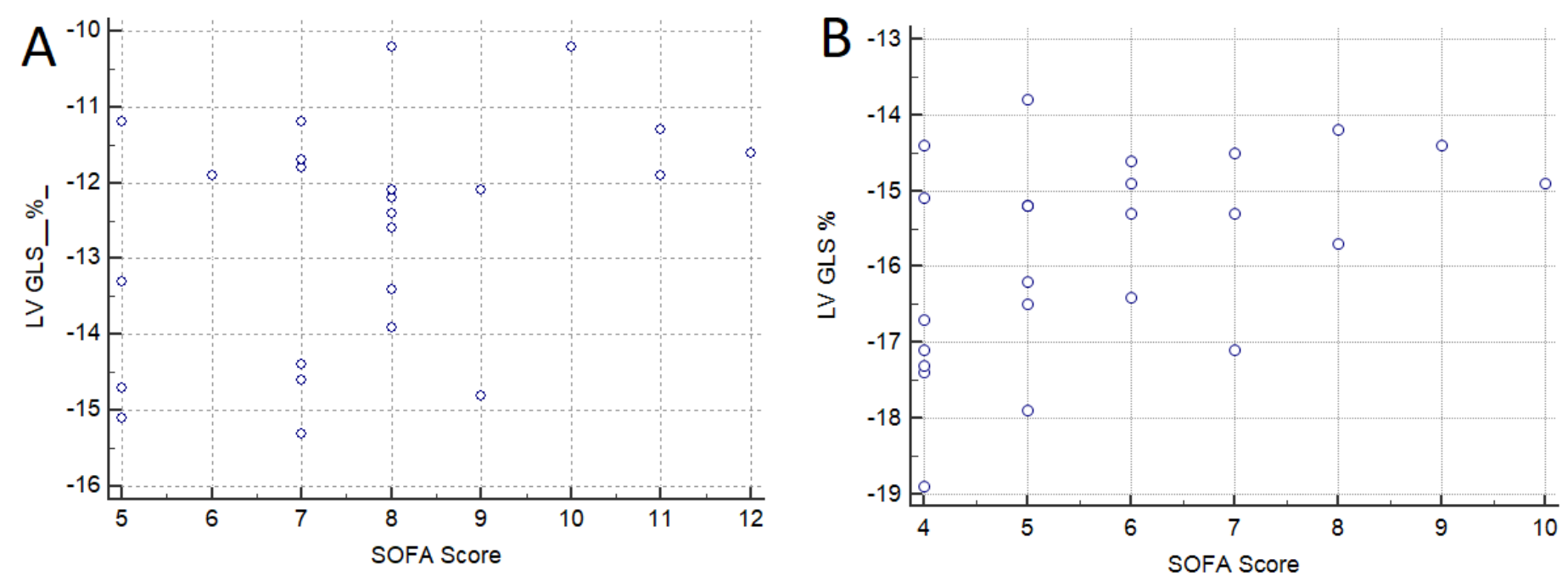

Figure (3): Scatter dots demonstrated the correlation between LV GLS and SOFA score in (A) Septic shock group, (B) Sepsis group. 


\begin{tabular}{|c|c|c|c|c|}
\hline \multicolumn{5}{|c|}{ Figure (6): Correlation between the clinical and echocardiological parameters and APACHE score } \\
\hline \multirow[t]{2}{*}{ Variables } & \multicolumn{2}{|c|}{ Septic shock } & \multicolumn{2}{|l|}{ Sepsis } \\
\hline & Correlation Co-efficient (r) & P-Value & Correlation Co-efficient (r) & P-Value \\
\hline Heart rate & 0.619 & $<0.001$ & -0.178 & 0.39 \\
\hline SBP & 0.187 & 0.37 & 0.156 & 0.45 \\
\hline DBP & -0.103 & 0.612 & -0.33 & 0.1 \\
\hline MAP & -0.214 & 0.303 & -0.34 & 0.09 \\
\hline EF \% & -0.915 & $<0.001$ & -0.804 & $<0.001$ \\
\hline $\mathrm{E}(\mathrm{cm} / \mathrm{sec})$ & -0.895 & $<0.001$ & 0.720 & $<0.001$ \\
\hline $\mathrm{A}(\mathrm{cm} / \mathrm{sec})$ & 0.794 & $<0.001$ & 0.31 & 0.12 \\
\hline E/A & 0.148 & 0.478 & 0.56 & 0.003 \\
\hline e & -0.739 & $<0.001$ & -0.887 & $<0.001$ \\
\hline a & -0.749 & $<0.001$ & -0.897 & $<0.001$ \\
\hline $\mathbf{e}^{\prime} / \mathbf{a}^{\prime}$ & 0.537 & $<0.001$ & 0.764 & $<0.001$ \\
\hline$E / \mathbf{e}^{-}$ & 0.289 & 0.16 & 0.847 & $<0.001$ \\
\hline LV GLS (\%) & 0.859 & $<0.001$ & 0.903 & $<0.001$ \\
\hline
\end{tabular}

Abbreviations; SBP = Systolic Blood Pressure, DBP = Diastolic Blood Pressure, MAP = Mean Arterial Pressure, $\mathbf{E F}=$ Ejection Fraction, $\mathrm{E}=$ maximum flow velocity during early LV diastolic filling, $\mathbf{A}=$ maximum flow velocity during late diastolic LV filling, LV GLS $=$ global systolic strain, $\mathbf{e}^{`}=$ Early diastolic annulus velocity, $\mathbf{a} `=$ late diastolic annulus velocity.
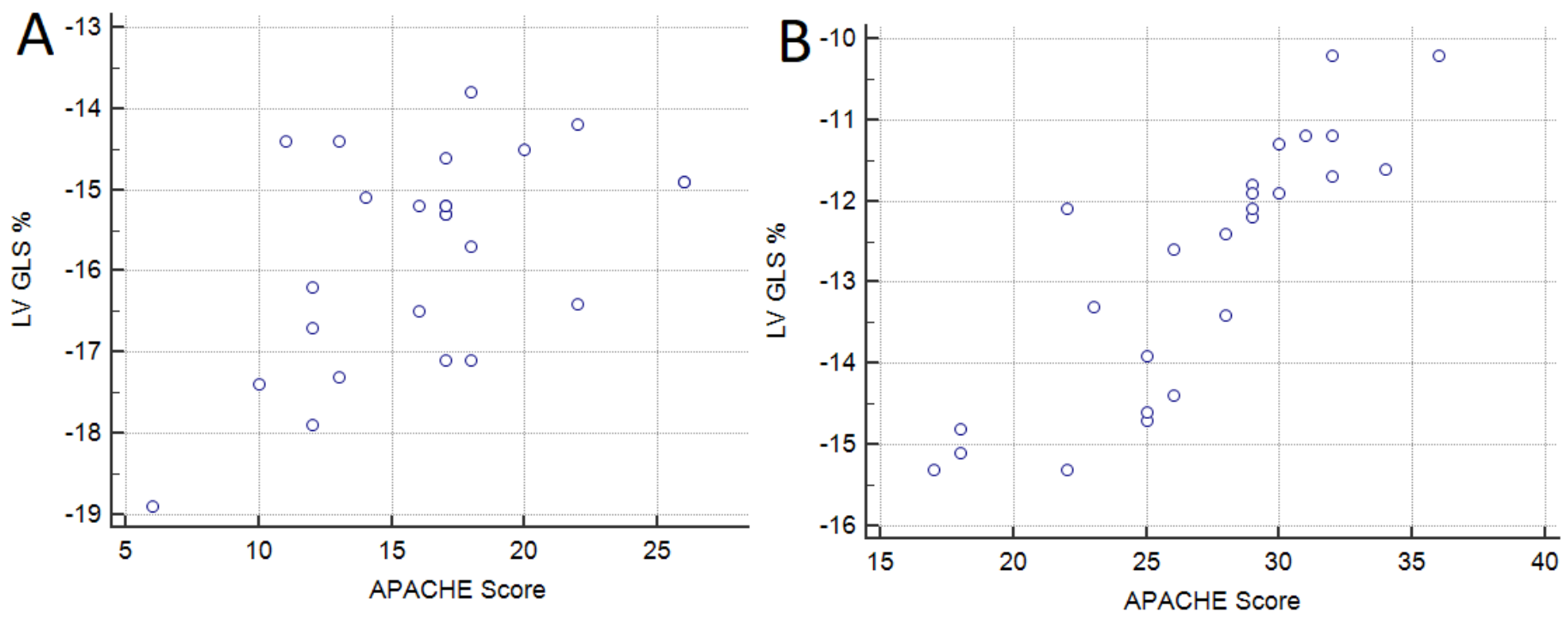

Figure (4): Scatter dots demonstrated the correlation between LV GLS and APACHE score in (A) Septic shock group, (B) Sepsis group.

(7): Univariate regression model to predict SOFA and APACH Scores among septic patients

\begin{tabular}{|c|c|c|c|c|}
\hline & \multicolumn{2}{|c|}{ SOFA Score } & \multicolumn{2}{c|}{ APACHE Score } \\
\cline { 2 - 5 } & $\boldsymbol{\beta}$ & P-Value & $\boldsymbol{\beta}$ & P-Value \\
\hline LV GLS (\%) & 0.608 & $<0.001$ & 0.968 & $<0.001$ \\
\hline EF \% & -0.597 & $<0.001$ & -0.854 & $<0.001$ \\
\hline E (cm/sec) & -0.262 & 0.066 & -0.41 & 0.003 \\
\hline A (cm/sec) & -0.057 & 0.69 & -0.216 & 0.13 \\
\hline e & -0.598 & $<0.001$ & -0.750 & $<0.001$ \\
\hline a & -0.397 & 0.004 & -0.65 & $<0.001$ \\
\hline
\end{tabular}

Abbreviations, LV GLS = global systolic strain, EF = Ejection Fraction, E = maximum flow velocity during early LV diastolic filling, A = maximum flow velocity during late diastolic LV filling, $\mathbf{e}^{`}=$ Early diastolic annulus velocity, $\mathbf{a} `=$ late diastolic annulus velocity. 
ejhm.journals.ekb.eg

\section{Outcomes}

There were three and two deaths among the septic shock and the septic groups. The mean days of ICU stay among the septic shock was $13.63 \pm 2.68$ while the sepsis group was $10.86 \pm 2.65$ that differed substantially $(\mathrm{p}=0.001)$. Additionally, acute kidney injury developed in 15 patients in the septic shock group and in 11 patients in the sepsis group. Subsequent to that, three and four patients experienced arrhythmias among the septic shock and the sepsis groups respectively (Figure 5).

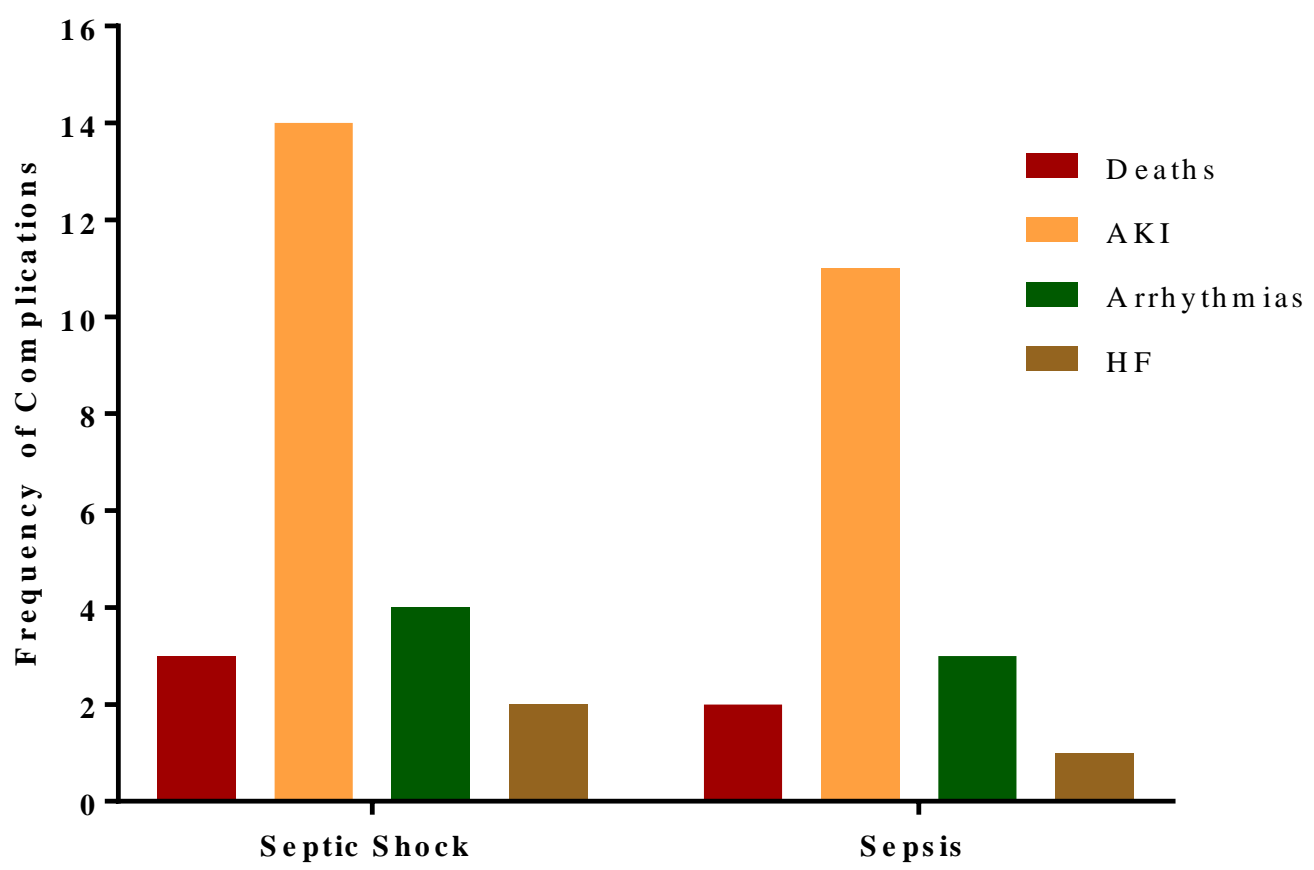

Figure (5): Bar chart delineated the pattern of complications among septic and septic shocked patients

\section{DISCUSSION}

Recently, the guidelines of Surviving Sepsis campaign focused on the early diagnosis and management of sepsis-related cardiomyopathy ${ }^{(\mathbf{1 9})}$. This is because the plurality of septic or septic shock patients developed myocardial insufficiency, even though those patients did not experience any symptoms or signs of cardiovascular dysfunction before death ${ }^{(20)}$. Furthermore, many studies evident the presence of a reversible sepsis-induced cardiac dysfunction, which requires intense management ${ }^{(21,22)}$. Thereafter, the current study was carried out to evaluate the impact of early detection of LV dysfunction using STE on the sepsis and septic shock outcomes.

The evidence abbreviated in the current investigation brings to light that STE plays a crucial rule in the early detection of LV dysfunction as a sequel of sepsis or septic shock. In particular septic patients, who diagnosed early using STE, experienced a lower rate of mortality and complications relative to patients with septic shock. In addition, LVGLS proved highly association with the sepsis outcomes in the terms of SOFA and APACHE scores. In addition, it was an independent predictor of sepsis sequels, whereas patients with high LVGLS were more vulnerable to experience bad consequences of sepsis and septic shock. Furthermore, the significant difference between sepsis and septic shook groups regarding the SOFA and APACHE scores brings to light that the early appreciation of LV dysfunction is a crucial factor for detection of sepsis outcomes.

Septic cardiomyopathy may be evolved as an eventual sequel of mitochondrial dysfunction, oxidative stress, myocardial injury and inflammatory process ${ }^{(23)}$. This phenomenon is difficult to be detected based on EF owed to the fact that it altered considerably by preload and after load ${ }^{(24)}$. On the one hand, more than $33 \%$ of patients with LVEF was missed when they were assessed using EF ${ }^{(25)}$.

In compliance with our results, Orde et al. ${ }^{(25)}$ notified that the predictive ability of STE in the detection of septic cardiomyopathy was relatively high when compared with convention Echocardiography. It is extremely pivotal to put into consideration that the normal values for STE are not internationally detected. On the contrary, the value at which the LV dysfunction was established was previously identified at $-15^{(25,26)}$. Subsequent to that, $\mathbf{N g}$ et al. ${ }^{(27)}$ reported that there was a statistically significant difference between the sepsis and the septic shock patients regarding the measurements of STE. however, conventional Echocardiographic measurements of the left ventricle failed to detect the difference between such groups.

The association between LV dysfunction and the prognosis of sepsis and septic shock was also examined in previous studies ${ }^{(28)}$. For instance, Innocenti et al. (29) showed that the prognostic value of LV systolic dysfunction was established and the positive correlation 
between LV dysfunction and SOFA score was also evolved.

STE has evolved as a direct, angle-independent, and a reproducible assessment of left ventricular function ${ }^{\left({ }^{(30)}\right.}$. Its employment in conditions such as cardiac impairment has shown a prognostic impact in the appreciation of left ventricular performance among critically ill patients (11). This is because it enables the early detection of hidden left ventricular impairment in the beginning of sepsis or septic shock ${ }^{(31)}$.

The present investigation had many limitations such as; it is a single-center study with a limited sample size, which reflect only a small number of populations. Additionally, the clinical spectrum of septic shock is highly dynamic and even though all patients were selected for the study within the first day of admission, time from primary presentation of disease to STE performance varies.

\section{CONCLUSIONS}

The capability of STE investigation for the detection of left ventricular dysfunction among septic or septic shocked critically ill patients is a promising and feasible approach. Thereafter, health care providers should employ STE as a routine investigation for such patients to reduce the potential consequences. However, large randomized clinical trials are mandatory to address the possible limitations of the present investigation.

\section{REFERENCES}

1. Riegel B, Huang L, Mikkelsen ME, Kutney- Lee A, Hanlon AL, Murtaugh CM et al. (2019): Early PostIntensive Care Syndrome among Older Adult Sepsis Survivors Receiving Home Care. J of the Am Geriatrics Soc., 67 (3): 5206.

2. Prout AJ, Talisa VB, Carcillo JA, Angus DC, Chang CCH, Yende S (2019): Epidemiology of Readmissions After Sepsis Hospitalization in Children. Hospital ped., 18 (4): 175-8.

3. Angus DC, Linde-Zwirble WT, Lidicker J, Clermont G, Carcillo J, Pinsky MR (2001): Epidemiology of severe sepsis in the United States: analysis of incidence, outcome, and associated costs of care. Crit care Med., 29 (7): 1303-10.

4. Markovic MT, Gottfredsson M, Mitic MT, Gaini S (2019):Epidemiology of community-acquired sepsis in the Faroe Islands-a prospective observational study. Infectious Diseases, 51 (1): 38-49.

5. Kakihana Y, Ito T, Nakahara M, Yamaguchi K, Yasuda T (2016): Sepsis-induced myocardial dysfunction: pathophysiology and management. J of intensive care, 4 (1): 22.

6. Suzuki T, Suzuki Y, Okuda J, Kurazumi T, Suhara T, Ueda T et al. (2017): Sepsis-induced cardiac dysfunction and $\beta$-adrenergic blockade therapy for sepsis. J of intensive care, 5 (1): 22.

7. Parker MM, Shelhamer JH, Bacharach SL, Green MV, Natanson C, Frederick TM et al. (1984): Profound but reversible myocardial depression in patients with septic shock. Ann of internal Med., 100 (4): 483-90.
8. Devasia T, Kareem H, Kumar YA, Kumar RP, Jose S, Prabhu SS et al. (2015): Cardiac Dysfunction in Patients with Sepsis, Severe Sepsis and Septic Shock. Br J of Med and Med Res. , 5 (4): 427.

9. Alvarez S, Vico T, Vanasco V (2016): Cardiac dysfunction, mitochondrial architecture, energy production, and inflammatory pathways: Interrelated aspects in endotoxemia and sepsis. The Int J of biochemistry \& cell biol., 81 (2): 30714.

10. Awany M, Tolba O, Al-Biltagi M, Al-Asy H, El-Mahdy H (2016): Cardiac Functions by Tissue Doppler and Speckle Tracking Echocardiography in Neonatal Sepsis and its Correlation with Sepsis Markers and Cardiac Troponin-T. J Ped Neonatal Care, 5 (3): 184-1.

11. Zaky A, Gill E, Paul C, Bendjelid K, Treggiari $M$ (2016): Characteristics of sepsis-induced cardiac dysfunction using speckle-tracking echocardiography: a feasibility study. Anaesthesia and intensive care, 44 (1): 65-76.

12. Zang $X$, Chen $W$, Sheng B, Zhao L, Gu X, Zhen J et al. (2018): Predictive value of early phrase echocardiography and cardiac biological markers in patients with severe sepsis: a five-year single-center retrospective study. Zhonghua wei zhong bing ji jiu yi xue., 30 (4): 332-6.

13. Wasyanto T (2015): APSC2015-1260 Cardiac Dysfunction: The Predictor of Severity and Mortality in Sepsis Patients at Dr. Moewardi Hospital Surakarta, an Echocardiography Study. Global Heart, 2 (10): e21-1.

14. Turillazzi E, Fineschi V, Palmiere C, Sergi C (2016): Cardiovascular involvement in sepsis. Mediators of Inflamm., 3 (5): $140-12$

15. Sanfilippo F, Santonocito C, Panarello G, Arcadipane A (2016): The role of speckle tracking echocardiography for prognostication in patients with severe sepsis or septic shock. Critical care, 20 (1): 284-5.

16. Lancellotti P, Tribouilloy C, Hagendorff A, Popescu BA, Edvardsen T, Pierard LA et al. (2013): Recommendations for the echocardiographic assessment of native valvular regurgitation: an executive summary from the European Association of Cardiovascular Imaging. Euro Heart J-Cardiovascular Imaging, 14 (7): 611-44.

17. Amundsen BH, Helle-Valle T, Edvardsen T, Torp H, Crosby J, Lyseggen E et al. (2006): Noninvasive myocardial strain measurement by speckle tracking echocardiography: validation against sonomicrometry and tagged magnetic resonance imaging. J of the Am College of Cardiol., 47 (4): 789-93.

18. Lang RM, Bierig M, Devereux RB, Flachskampf FA, Foster E, Pellikka PA et al. (2006): American society of echocardiography's Nomenclature and standards Committee; task Force on Chamber Quantification; American College of Cardiology echocardiography Committee; American Heart Association; european Association of echocardiography, european society of Cardiology. Recommendations for chamber quantification. Eur J Echocardiogr. ,7 (2): 79-108.

19. Dellinger RP, Levy MM, Rhodes A, Annane D, Gerlach H, Opal SM et al. (2013): Surviving Sepsis Campaign: international guidelines for management of severe sepsis and septic shock, 2012. Intensive care Med., 39 (2): 165-228.

20. Torgersen C, Moser P, Luckner G, Mayr V, Jochberger S, Hasibeder WR et al. (2009): Macroscopic postmortem findings in 235 surgical intensive care patients with sepsis. Anesthesia \& Analgesia, 108 (6): 1841-7. 
21. Joulin O, Marechaux S, Hassoun S, Montaigne D, Lancel S, Neviere R (2009): Cardiac force-frequency relationship and frequency-dependent acceleration of relaxation are impaired in LPS-treated rats. Critical Care, 13 (1): R14-198.

22. Ricard-Hibon A, Losser M-R, Kong R, Belouci S, Teisseire B, Pay D (1998): Systemic pressure-flow reactivity to norepinephrine in rabbits: impact of endotoxin and fluid loading. Intensive care medicine, 24 (9): 959-66.

23. Vieillard-Baron A (2011): Septic cardiomyopathy. Ann of intensive care, 1 (1): 60-2.

24. Cimolai M, Alvarez S, Bode C, Bugger H (2015): Mitochondrial mechanisms in septic cardiomyopathy. In $\mathrm{J}$ of Molecular Sciences, 16 (8): 17763-78.

25. Orde SR, Pulido JN, Masaki M, Gillespie S, Spoon JN, Kane GC et al. (2014): Outcome prediction in sepsis: speckle tracking echocardiography based assessment of myocardial function. Critical Care, 18 (4): R149.

26. Lang RM, Badano LP, Mor-Avi V, Afilalo J, Armstrong A, Ernande L et al. (2015): Recommendations for cardiac chamber quantification by echocardiography in adults: an update from the American Society of Echocardiography and the European Association of Cardiovascular Imaging. Eur Heart J-Cardiovascular Imaging, 16 (3): 233-71.

27. Ng PY, Sin WC, Ng AK-Y, Chan WM (2016): Speckle tracking echocardiography in patients with septic shock: a case control study (SPECKSS). Critical Care, 20 (1): 145.

28. Beesley SJ, Weber G, Sarge T, Nikravan S, Grissom CK, Lanspa MJ et al. (2018): Septic cardiomyopathy. Critical care Med., 46 (4): 625-34.

29. Innocenti F, Palmieri V, Guzzo A, Stefanone VT, Donnini C, Pini R (2018): SOFA score and left ventricular systolic function as predictors of short-term outcome in patients with sepsis. Internal and emergency Med., 13 (1): 51 8.

30. Collier P, Phelan D, Klein A (2017): A test in context: myocardial strain measured by speckle-tracking echocardiography. J of the Am College of Cardiol., 69 (8): 1043-56.

31. Paredes SG, Vogliotti I, Colque R, Tibaldi MA (2017): Prognostic value of ventricular function assessed by speckle tracking echocardiography in patients with sepsis. Critical care, 18 (1): 56-420. 